\title{
The Role of Collagen Quaternary Structure in the Platelet:Collagen Interaction
}

\author{
Lawrence F. Brass and Howard B. Bensusan \\ From the Department of Biochemistry, Case Western Reserve University, \\ Cleveland, Ohio 44106
}

A B S T R A C T We have investigated whether collagen quaternary structure is required for the platelet: collagen interaction. Quaternary structure refers to the assembly of collagen monomers (tropocollagen) into polymers (native-type fibrils). Purified monomeric collagen was prepared from acetic acid extracts of fetal calfskin. Polymeric collagen was prepared by dispersion of bovine Achilles tendon collagen and by incubation of monomeric collagen at $37^{\circ} \mathrm{C}$ and $\mathrm{pH}$ 7.4. The state of polymerization was confirmed by electron microscopy. Release of platelet serotonin in the absence of platelet aggregation was used to determine the effectiveness of the platelet: collagen interaction. All forms of collagen produced serotonin release only after a lag period, but polymeric collagen gave a shorter lag period than did monomeric collagen. Monomeric collagen was also quanidinated selectively to convert collagen lysine groups to homoarginine, while leaving the arrangement of polar groups intact. Guanidination of monomeric collagen increased the rate of polymerization and reduced the lag time in serotonin release. Glucosamine (17 $\mathrm{mM})$ retarded polymerization and inhibited the release of platelet serotonin by monomeric collagen but had little effect on release produced by thrombin or polymeric collagen. At the same concentration, glucosamine did not reduce the sensitivity of platelets to stimulation by collagen or block the platelet: collagen interaction. The only effect of glucosamine was on the collagen: collagen interaction. Galactosamine had a similar effect, but glucose, galactose, and $N$-acetylglucosamine had no effect. We conclude from this data that collagen monomers cannot effectively interact with platelets and that, therefore, collagen quaternary structure has a role in the recognition of collagen by platelets.

L. F. Brass is a predoctoral trainee of the NIH. This work was performed in partial fulfillment of the requirements of the M.D.-Ph.D. degree at Case Western Reserve University, Department of Biochemistry.

Received for publication 21 May 1974 and in revised form 19 August 1974.

\section{INTRODUCTION}

When platelets are exposed to collagen, either in vivo or in vitro, they adhere to it and release specific intracellular components, including $\mathrm{ADP}, \mathrm{Ca}^{++}$, and serotonin $(1,2)$. The ADP and $\mathrm{Ca}^{++}$are essential for the subsequent platelet: platelet interactions that lead to the formation of platelet aggregates (3). Several attempts have been made to determine which portions of the collagen molecule are required for the platelet: collagen interaction. At present there is evidence indicating that an intact tertiary structure (4), an ordered array of polar groups $(5,6)$, and hydroxylysine-linked carbohydrate groups (7-11) may all be necessary for the recognition of collagen by platelets.

We have investigated the role of collagen quaternary structure in the platelet: collagen interaction. Quarternary structure refers to the lateral association of collagen monomers into polymers in which the monomers are arranged parallel to each other, but staggered by approximately one quarter of their length (12). The term "monomer" will refer to what is usually called tropocollagen. The monomer is a molecule of molecular weight of approximately 300,000 daltons, composed of three polypeptide chains. These chains, in the form of extended left-handed helices, are twisted into a righthanded super helix approximately 2,800 $\AA$ long. We have investigated whether collagen monomers as well as polymers can interact with platelets.

Some explanation of the experimental approach taken in this paper is required. Normally, the formation of platelet aggregates is used to measure the extent of the interaction of collagen with platelets. We have used the platelet release reaction instead. Not only is the release reaction several steps closer to the actual platelet: collagen interaction, but it has been shown (13) that small amounts of collagen, insufficient by themselves to stimulate the platelet maximally, can act synergistically with released ADP to produce near-maximal platelet aggregation. This implies that a decrease in the amount of ef- 
fective collagen, which would certainly be detected in a release assay, might go undetected in an assay of aggregation. Specifically, we measured the release from the platelet of exogenously supplied $\left[{ }^{3} \mathrm{H}\right]$ serotonin. The exogenous $\left[{ }^{3} \mathrm{H}\right]$ serotonin has been shown to be indistinguishable from endogenous serotonin throughout storage and release (14). To prevent additional serotonin from being released by subsequent platelet: platelet interactions, EDTA was added to chelate $\mathrm{Ca}^{++}$and the platelets were washed to reduce their sensitivity to further stimulation by released $\operatorname{ADP}(15,16)$.

\section{METHODS}

Acid-soluble (monomeric) collagen. Acid-soluble (AS) ${ }^{1}$ collagen was prepared from fetal calfskin (Pel-Freez, BioAnimals, Inc., Rogers, Ark.). Unless otherwise noted, all steps were carried out at $4^{\circ} \mathrm{C}$. The hairless skin was scraped free of subcutaneous fat, ground, washed with 0.01 $\mathrm{M}$ phosphate buffer ( $\mathrm{pH} 7.4$ ), and extracted twice with 0.5 $\mathrm{M} \mathrm{NaCl}$. The remaining tissue was extracted twice with $0.1 \mathrm{M}$ acetic acid. The acetic acid extracts were pooled and the collagen was precipitated by adding $\mathrm{KCl}$ to $16 \%$. The precipitate was redissolved by stirring it overnight in $0.1 \mathrm{M}$ acetic acid. Undissolved material was removed by centrifugation for $30 \mathrm{~min}$ at $9,750 \mathrm{~g}$. The supernatant liquid was readjusted to $\mathrm{pH} 7.4$ and warmed to $29^{\circ} \mathrm{C}$, allowing the collagen to polymerize into a thick clot. The clot was collected by centrifugation $\left(30 \mathrm{~min}\right.$ at $9,750 \mathrm{~g}$ and $24^{\circ} \mathrm{C}$ ) and redissolved by stirring it overnight in $0.1 \mathrm{M}$ acetic acid. The cycle of clotting and re-solution was repeated twice and the final collagen solution $(1.5 \mathrm{mg} / \mathrm{ml})$ was stored frozen at $-10^{\circ} \mathrm{C}$. Just before use, portions were dialyzed against $0.01 \mathrm{M}$ acetic acid. The final concentrations in assay mixtures ranged from 30 to $100 \mu \mathrm{g} / \mathrm{ml}$.

To check for the presence of polymers, a sample of the monomer solution was allowed to form lateral, parallel aggregates of long-spaced segments (SLS) by the addition of ATP (17). Examination of the SLS structures in an electron microscope showed that the original solution contained only monomers, since there was a complete absence of doublets. Doublets are form when dimers are the nuclei for SLS formation.

Polymerized collagen. Dispersed bovine Achilles tendon collagen was obtained from Ethicon, Inc. (Somerville, N. J.). This material was diluted and then dialyzed against $0.01 \mathrm{M}$ acetic acid. Final concentrations in assay mixtures ranged from 30 to $100 \mu \mathrm{g} / \mathrm{ml}$. Examination of this material in an electron microscope confirmed that it was polymeric.

Guanidinated collagen. AS collagen was treated as previously described with 1-guanyl-3,5-dimethylpyrazole nitrate as the guanidinating agent (18). The extent of guanidination varied with the reaction time and was determined by measuring the conversion of collagen lysine to homoarginine. Amino acid analyses were performed on a Bio-Cal 200 amino acid analyzer (Bio-Cal Instrument Co., Richmond, Calif.) after acid hydrolysis for $16 \mathrm{~h}$ in $6 \mathrm{~N} \mathrm{HCl}$ at $110^{\circ} \mathrm{C}$. Before use, the guanidinated collagen was dialyzed into $0.1 \mathrm{M}$ acetic acid. Final concentrations in the assay mixtures ranged from 30 to $60 \mu \mathrm{g} / \mathrm{ml}$.

\footnotetext{
1 Abbreviations used in this paper: AS, acid-soluble; SLS, long-spaced segments.
}

Polymerization. Polymerization was observed in a Gilford spectrophotometer (Gilford Instrument Laboratories, Inc., Oberlin, Ohio) at $290 \mathrm{~nm}$, with a circulating water bath to maintain temperature in the cuvettes at $37^{\circ} \mathrm{C} .1 \mathrm{ml}$ of resuspension buffer (see below) was mixed with $0.1 \mathrm{ml}$ of monomeric collagen solution and, where appropriate, 0.1 $\mathrm{ml}$ of inhibitor solution. Polymerization was reflected by an increase in optical density (19).

Platelets. Whole blood $(60 \mathrm{ml})$ was collected by venopuncture from healthy donors who had not ingested any drug known to affect platelets, including aspirin and oral contraceptives, within the preceding 2 wk. The blood was anticoagulated with EDTA (final concentration $6 \mathrm{mM}$ ) at $\mathrm{pH} 7.4$ and centrifuged $5 \mathrm{~min}$ at $260 \mathrm{~g}$. The supernatant platelet-rich plasma (approximately $20 \mathrm{ml}$ ) was removed and incubated for $1 \mathrm{~h}$ at $18^{\circ} \mathrm{C}$ with $2.7 \mathrm{nmol}$ of $\left[{ }^{8} \mathrm{H}\right]$ serotonin. Under these conditions, the platelets incorporated $80-90 \%$ of the exogenous serotonin. The platelets were collected by centrifugation (10 $\mathrm{min}$ at $1,475 \mathrm{~g}$ ) and resuspended in a solution containing $\mathrm{NaCl}(140 \mathrm{mM})$, Tris $(25 \mathrm{mM})$, EDTA $(0.3 \mathrm{mM})$, and glucose $(5 \mathrm{mM})$ at $\mathrm{pH}$ 7.4 (20). Remaining red blood cells were removed by centrifugation for $5 \mathrm{~min}$ at $50 \mathrm{~g}$. All steps were at $4^{\circ} \mathrm{C}$ unless otherwise noted. Either silicone-coated glassware or plastic containers were used throughout. The washed platelets were prepared and used within $3-4 \mathrm{~h}$ of the time the blood was drawn. There was no loss of responsiveness to collagen during this period. Final platelet concentrations ranged from 1 to $3 \times 10^{8}$ cells $/ \mathrm{ml}$, as determined by light microscopy.
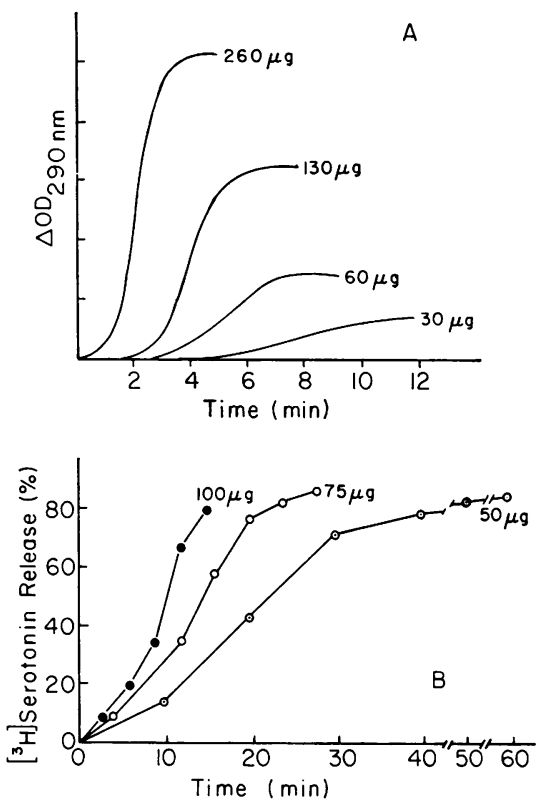

FIgURE 1 The effect of concentration on polymerization and serotonin release by monomeric collagen. (A) Polymerization. $1 \mathrm{ml}$ of resuspension buffer was incubated at $37^{\circ} \mathrm{C}$ in a Gilford spectrophotometer with $0.1 \mathrm{ml}$ of monomeric (AS) collagen in the amounts shown. (B) Serotonin release. $1 \mathrm{ml}$ of washed platelets containing $\left[{ }^{3} \mathrm{H}\right]$ serotonin was mixed with $0.1 \mathrm{ml}$ of monomeric collagen (amounts shown) and incubated at $37^{\circ} \mathrm{C}$. The final platelet concentration was $1.0 \times 10^{8} \mathrm{cells} / \mathrm{ml}$. A 60 -min incubation without collagen gave $3 \%$ release.

The Platelet:Collagen Interaction 

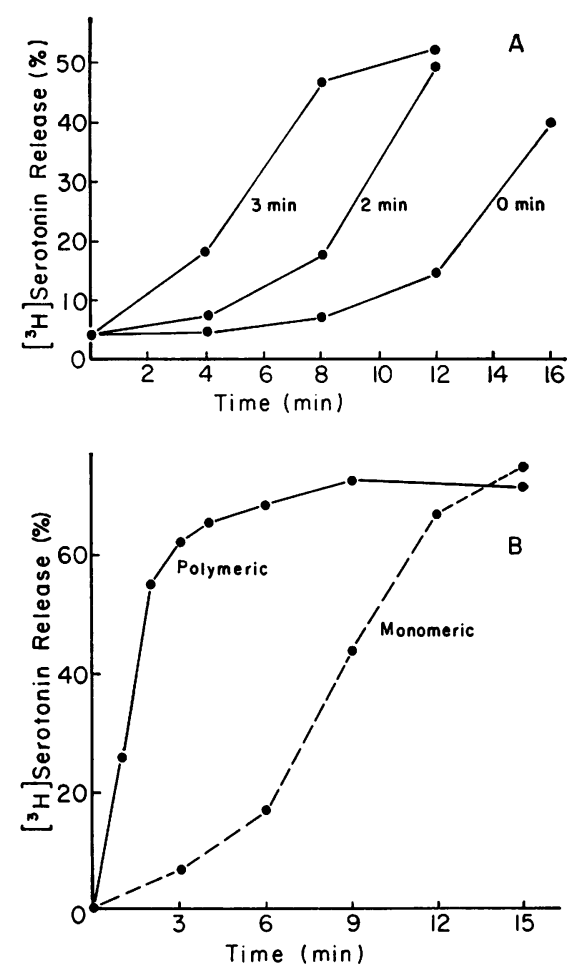

FIGURE 2 Serotonin release by polymeric collagen. (A) Polymerized monomeric (AS) collagen. Monomeric collagen $(30 \mu \mathrm{g}$ in $0.1 \mathrm{ml})$ was polymerized by incubation in $0.5 \mathrm{ml}$ resuspension buffer at $37^{\circ} \mathrm{C}$ for 0,2 , or $3 \mathrm{~min}$ before the addition of $0.5 \mathrm{ml}$ washed platelets. The final platelet concentration was $1.5 \times 10^{8} \mathrm{cells} / \mathrm{ml}$. (B) Polymeric (dispersed bovine tendon) collagen. $1 \mathrm{ml}$ of washed platelets was incubated at $37^{\circ} \mathrm{C}$ with $0.1 \mathrm{ml}$ of either monomeric or polymeric collagen $(100 \mu \mathrm{g})$. The final platelet concentration was $1.2 \times 10^{8}$ cells $/ \mathrm{ml}$.

$\left[{ }^{8} \mathrm{H}\right]$ serotonin $\left(\left[1,2-{ }^{8} \mathrm{H}\right](N)-5\right.$-hydroxytryptamine $)$ was obtained from New England Nuclear (Boston, Mass.) and was not diluted with nonradioactive serotonin. The specific activity was $1.5 \mathrm{Ci} / \mathrm{mmol}$.

TABLE I

Extent of Guanidination of Monomeric Collagen

\begin{tabular}{lccc}
\hline Collagen & Time* & $\begin{array}{c}\text { Lysine } \\
\text { content }\end{array}$ & Guanidination \\
\hline & $h$ & & $\%$ \\
AS & 0 & 27.0 & 0 \\
G3 & 3 & 24.2 & 10 \\
G5 & 5 & 22.5 & 17 \\
G8 & 8 & 21.3 & 21 \\
G12 & 12 & 18.1 & 33 \\
G24 & 24 & 16.6 & 38 \\
\hline
\end{tabular}

${ }^{*} \mathrm{H}$ of incubation at $0^{\circ} \mathrm{C}$ with 1-guanyl-3,5-dimethypyrazole nitrate.

$\ddagger$ Residues $/ 1,000$ residues.
Serotonin release $(21,22) .1 \mathrm{ml}$ of washed platelets was mixed with $0.1 \mathrm{ml}$ of initiator solution (collagen or thrombin) and, where appropriate, $0.1 \mathrm{ml}$ of inhibitor solution in a 3-ml plastic centrifuge tube. Final $\mathrm{pH}$ was 7.4. After incubation at $37^{\circ} \mathrm{C}$ in a water bath, the tubes were cooled on ice to stop the reaction and centrifuged for $15 \mathrm{~min}$ at $2,450 \mathrm{~g}$ at $4^{\circ} \mathrm{C}$. The supernates, containing the $\left[{ }^{8} \mathrm{H}\right]$ serotonin released by the platelets, were sampled twice and counted in a Beckman liquid scintillation counter (Beckman Instruments, Inc., Fullerton, Calif.). All experiments were performed in duplicate.

The percent of intracellular $\left[{ }^{8} \mathrm{H}\right]$ serotonin released was calculated by the following formula: $\%$ release $=(X-E C)$ IC) $\times 100$ where $X$ is the supernate counts, $E C$ the extracellular counts, and $I C$ the intracellular counts. The extracellular counts were determined by pelleting the platelets from 1-ml samples of the washed platelet preparation (15 min, $2,450 \mathrm{~g}$ ) and counting ${ }^{8} \mathrm{H}$ in the supernatant fluid. The extracellular counts were approximately $5 \%$ of the total counts. The intracellular counts were determined by sampling the washed platelet preparation directly and subtracting the extracellular counts. Up to $80 \%$ of the intracellular serotonin was released by collagen. When $0.1 \mathrm{ml}$ of acetic acid $(0.01 \mathrm{M})$ was substituted for collagen, less than $5 \%$ of the intracellular counts were released. In some of the experiments, monomeric collagen was incubated at $37^{\circ} \mathrm{C}$ in $0.5 \mathrm{ml}$ resuspension buffer before the platelets were added in $0.5 \mathrm{ml}$ of buffer.

This technique gives results that are qualitatively but not necessarily quantitatively reproducible from day to day. To allow for this, the appropriate controls were included with each day's experiments.

Thrombin. Topical bovine thrombin (Parke, Davis \& Company. Detroit, Mich.) was dissolved in isotonic barbital/saline buffer ( $\mathrm{pH} 7.4$ ) and used without further purification. The final concentration in the assay mixtures was approximately $0.4 \mathrm{NIH} \mathrm{U} / \mathrm{ml}$.

Protein. The biuret method was used for determinations of protein concentration (23).

\section{RESULTS}

At $4^{\circ} \mathrm{C}$ and low $\mathrm{pH}$, AS collagen will remain in solution as monomers. At $37^{\circ} \mathrm{C}$ and $\mathrm{pH} 7.4$, polymerization

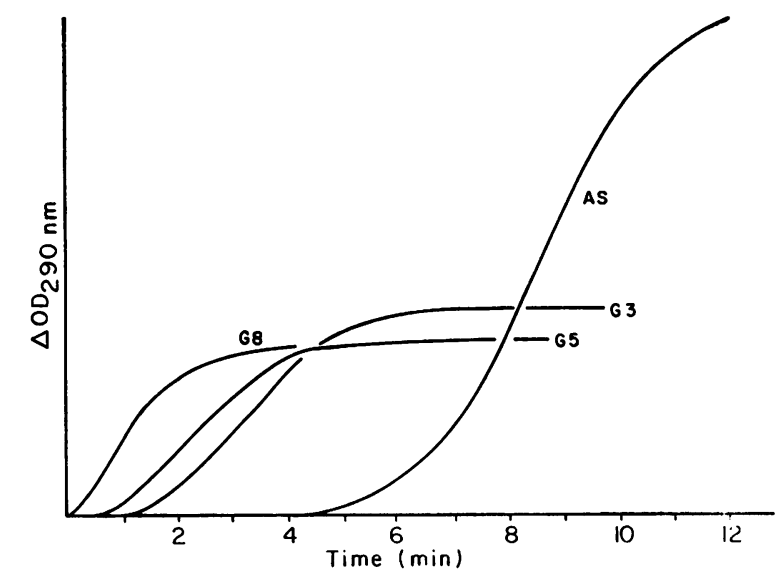

FIgURE 3 Polymerization of guanidinated monomeric collagen. $1 \mathrm{ml}$ of resuspension buffer was incubated at $37^{\circ} \mathrm{C}$ with $0.1 \mathrm{ml}$ of collagen (33 $\mu \mathrm{g})$. The collagen was $21 \%$ (G8), 17\% (G5), 10\% (G3), or 0\% (AS) guanidinated. 

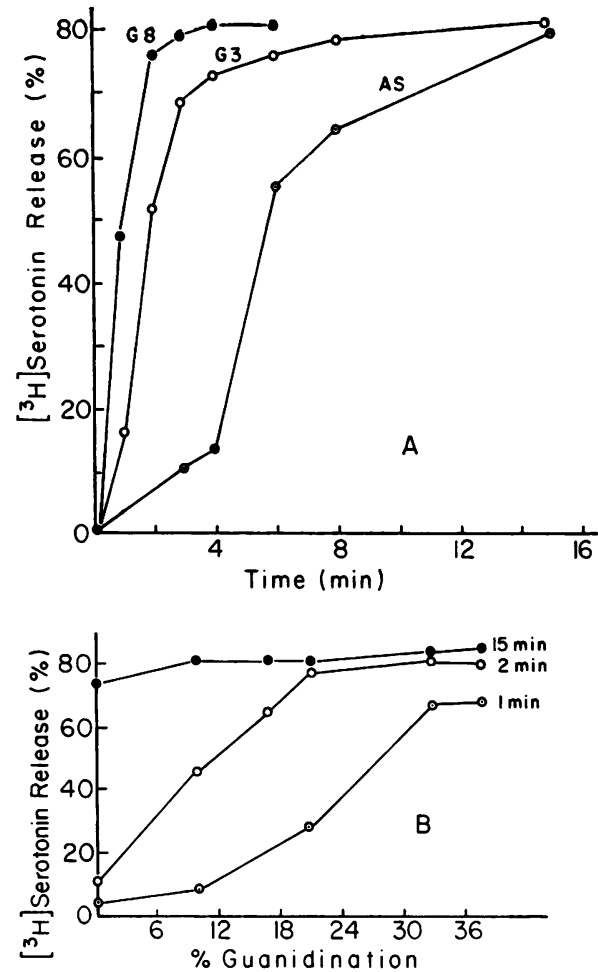

FIgURE 4 The effect of guanidination of monomeric collagen on serotonin release. $1 \mathrm{ml}$ of washed platelets was incubated at $37^{\circ} \mathrm{C}$ with $0.1 \mathrm{ml}$ of monomeric collagen (65 $\mu \mathrm{g})$. The final platelet concentration was $1.3 \times 10^{8}$ cells $/ \mathrm{ml}$. (A) Time course of serotonin release by monomeric collagen that is $21 \%$ (G8), $10 \%$ (G3), or $0 \%$ (AS) guanidinated. (B) Serotonin release at 1,2 , and $15 \mathrm{~min}$ as a function of percent of guanidination.

occurs. There is an initial lag period, followed by a rapid growth phase and a final leveling-off at the full extent of the reaction (Fig. 1A). Increasing the collagen concentration increases the rate and final change in optical density while decreasing the lag time. Collageninduced serotonin release from platelets follows a similar pattern, except that the final extent of release is not as sensitive to the collagen concentration as is the final extent of polymerization (Fig. 1B).

If monomeric collagen must polymerize before it can interact with platelets, it should be possible to decrease the lag time in serotonin release by allowing the collagen to form polymers before it is added to the platelets. In the experiment shown in Fig. 2A, monomeric collagen $(30 \mu \mathrm{g})$ was polymerized by incubation at $37^{\circ} \mathrm{C}$ and $\mathrm{pH} 7.4$ in $0.5 \mathrm{ml}$ of resuspension buffer before the platelets were added in a further $0.5 \mathrm{ml}$ of buffer. Incubating the collagen by itself for 2 or $3 \mathrm{~min}$ was sufficient to shorten the lag time in serotonin release greatly.
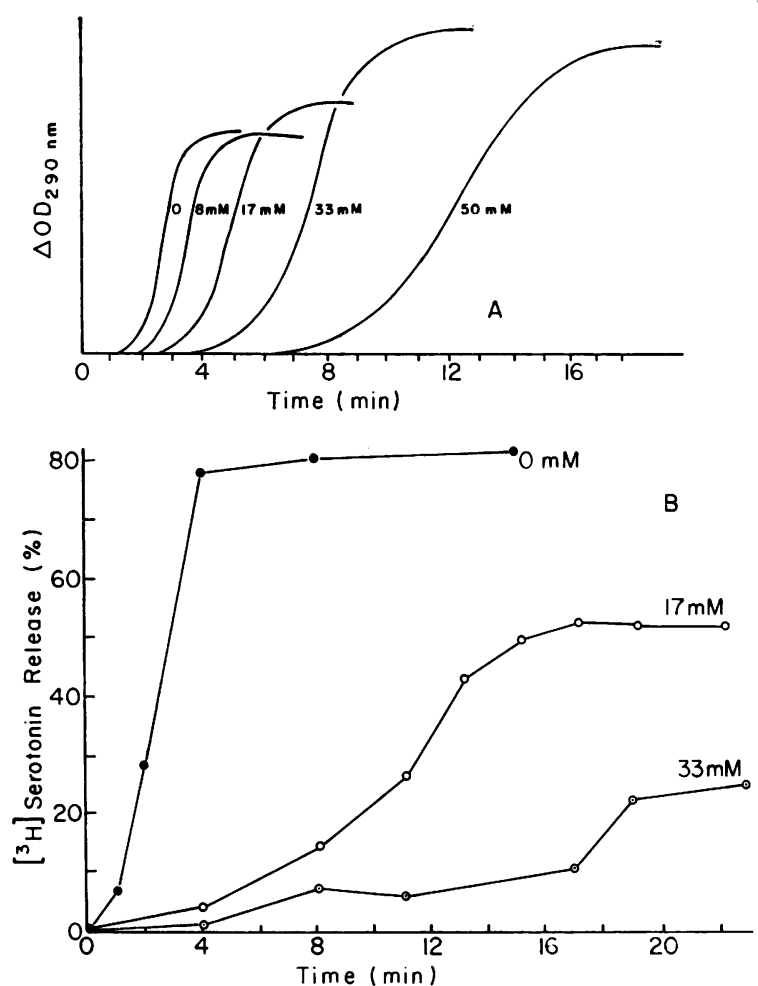

FIgURE 5 The effect of glucosamine on monomeric collagen. (A) Polymerization. $1 \mathrm{ml}$ of resuspension buffer was mixed with $0.1 \mathrm{ml}$ of monomeric collagen $(130 \mu \mathrm{g})$ and $0.1 \mathrm{ml}$ glucosamine solution (final concentration shown) and incubated at $37^{\circ} \mathrm{C}$ in a Gilford spectrophotometer. (B) Serotonin release. $1 \mathrm{ml}$ of washed platelets was incubated at $37^{\circ} \mathrm{C}$ with the same amount of collagen and glucosamine. The final platelet concentration was $2.0 \times 10^{8}$ cells $/ \mathrm{ml}$.

Polymerized collagen was also prepared by dispersion of bovine Achilles tendon collagen. When added to washed platelets, this collagen produced serotonin release with a much shorter lag time than when an equal amount of monomeric collagen was used (Fig. 2B).

Effect of guanidination. Monomeric collagen was guanidinated by reaction with 1-guanyl-3,5-dimethylpy-

TABLE II

Effect of Glucosamine on Thrombin- and Collagen-Induced Serotonin Release

\begin{tabular}{|c|c|c|c|}
\hline \multirow[b]{2}{*}{ Protein } & \multicolumn{2}{|c|}{ Release } & \multirow[b]{2}{*}{ Inhibition } \\
\hline & $+\mathrm{H}_{2} \mathrm{O}$ & +Glucosamine & \\
\hline & \multicolumn{2}{|c|}{$\%$} & $\%$ \\
\hline Thrombin & 81.7 & 79.6 & 3 \\
\hline Collagen & 84.5 & 28.8 & 66 \\
\hline
\end{tabular}

* The assay mixture included $1.0 \mathrm{ml}$ washed platelets, $0.1 \mathrm{ml}$ AS collagen $(100 \mu \mathrm{g})$ or thrombin $(0.5 \mathrm{NIH} \mathrm{U})$, and $0.1 \mathrm{ml}$ $\mathrm{H}_{2} \mathrm{O}$ or glucosamine (final concn., $17 \mathrm{mM}$ ), incubated at $37^{\circ} \mathrm{C}$ for $15 \mathrm{~min}$. Platelet concentration was $2 \times 10^{8}$ cells $/ \mathrm{ml}$.

The Platelet:Collagen Interaction

1483 
razole nitrate. The extent of guanidination varied with the reaction time (Table I). The guanidinated collagen showed a greatly reduced lag time in both polymerization (Fig. 3) and serotonin release (Fig. 4). The greater the extent of guanidination, the greater the reduction in the lag times. The collagen samples that were the most guanidinated gave lag times too short for our assays to measure accurately, i.e., less than $30 \mathrm{~s}$. To produce the curves shown in Fig. 3, the rate of polymerization had to be slowed by using a lower collagen concentration than in Fig. 4.

Effect of glucosamine. Glucosamine has been reported to retard collagen-induced platelet aggregation (24-26). In our experiments, when glucosamine was added to the platelets along with monomeric collagen, it increased the lag time in both polymerization (Fig. 5A) and serotonin release (Fig. 5B) and decreased the final extent of release. At the same concentration, glucosamine had no effect on thrombin-induced release (Table II) and only a small effect on release induced by polymerized collagen (Table III). Theoretically, glucosamine might have been affecting the platelets, as well as the collagen, either by competing with collagen for the collagen binding site on the platelet or by decreasing the ability of the platelets to respond to the collagen stimulus. The results with polymerized collagen and thrombin indicate that these possibilities are not likely. In addition, the following experiment was performed. If glucosamine affects the platelets, increasing the platelet concentration in the presence of a fixed amount of glucosamine and an excess of monomeric collagen should dilute the inhibitor and increase the percent of intracellular serotonin released. Alternatively, if glucosamine exerts its effects solely on collagen, increasing the platelet concentration should decrease the percent of intracellular serotonin released by decreasing the ratio of effective collagen to platelets. Over a 50 -fold range in platelet concentration there is, in the absence of glucosamine, little change in

TABLE III

Effect of Glucosamine on Serotonin Release by Polymeric Collagen

\begin{tabular}{lcccc}
\hline & \multicolumn{4}{c}{ Release } \\
\cline { 3 - 4 } \multicolumn{1}{c}{ Collagen } & glcNH & \\
\cline { 3 - 4 } & $m M$ & $+\mathrm{H}_{2} \mathrm{O}$ & + glcNH$_{2}$ & Inhibition \\
\hline Monomeric & 34 & 74.9 & $\%$ & $\%$ \\
Polymeric & 34 & 60.2 & 42.3 & 88 \\
Monomeric & 17 & 74.9 & 17.3 & 77 \\
Polymeric & 17 & 60.2 & 49.8 & 17 \\
\hline
\end{tabular}

The assay mixture included $1.0 \mathrm{ml}$ washed platelets, $0.1 \mathrm{ml}$ monomeric or polymeric collagen $(100 \mu \mathrm{g})$, and $0.1 \mathrm{ml}$ glucosamine (final concentration shown) or $\mathrm{H}_{2} \mathrm{O}$, incubated at $37^{\circ} \mathrm{C}$ for $15 \mathrm{~min}$. Platelet concentration was $1.4 \times 10^{8} \mathrm{cells} / \mathrm{ml}$.

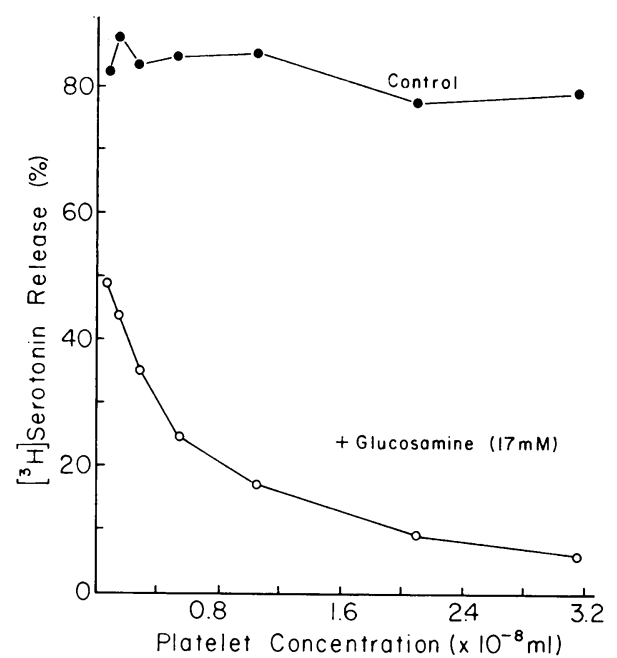

FIGURE 6 The effect of platelet concentration on inhibition of serotonin release by glucosamine. $1 \mathrm{ml}$ of washed platelets was incubated at $37^{\circ} \mathrm{C}$ for $15 \mathrm{~min}$ with $0.1 \mathrm{ml}$ of monomeric collagen $(100 \mu \mathrm{g})$ and with $0.1 \mathrm{ml}$ of either $\mathrm{H}_{2} \mathrm{O}$ (control curve) or glucosamine (final concentration, 17 $\mathrm{mM})$. The final platelet concentration varied over a 50 fold range from 0.6 to $3.1 \times 10^{8}$ cells $/ \mathrm{ml}$.

the amount of serotonin released by $100 \mu \mathrm{g}$ of monomeric collagen (Fig. 6). In the presence of glucosamine (17 $\mathrm{mM})$, however, the percent of intracellular serotonin released decreases as platelet concentration increases, demonstrating that glucosamine has no apparent effect on the platelets or on the platelet: collagen interaction. This experiment confirms the results with polymerized collagen and thrombin and excludes the possibility that dispersed bovine Achilles tendon collagen is not inhibited by glucosamine because it interacts with platelets differently from polymerized acid-soluble collagen.

To explore further the basis for inhibition by glucosamine, other related sugars were investigated for their ability to act as inhibitors. Galactosamine (17 $\mathrm{mM}$ ) retarded polymerization and release to the same degree as glucosamine, but glucose, galactose, and $N$-acetylglucosamine at the same concentration had no inhibitory effect.

\section{DISCUSSION}

We have investigated the role of collagen quaternary structure in the platelet: collagen interaction. Specifically, we have asked whether collagen monomers can effectively interact with platelets to stimulate the platelet release reaction. Because of the difficulty in stabiliz-

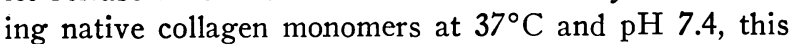
question can be asked only indirectly. The experiments described in this paper fall into three groups: (a) Comparison of initially monomeric and polymeric collagen 
for their relative effectiveness in producing the release reaction; $(b)$ determination of the effect that accelerating polymerization has on the rate of release produced by collagen that is initially monomeric; and (c) determination of the effect that inhibiting polymerization has on release. Release of $\left[{ }^{3} \mathrm{H}\right]$ serotonin was used to assess the effectiveness of the platelet: collagen interaction.

There is a lag period when collagen produces the platelet release reaction. The length of the lag period is dependent on the amount and type of collagen present. It can be greatly shortened either by increasing the collagen concentration, by allowing the collagen to pre-polymerize, or by using collagen that is already polymeric. All of these observations are consistent with the lag period due in part to the time required for polymers to form.

Similarly, work by other investigators has shown that changes made in collagen that delay polymerization also delay collagen-induced aggregation. These changes include exposure to trypsin or X-rays (27) and limited digestion with collagenase (28). Unfortunately, the delay produced in aggregation after treatment by these methods may have been due to the destruction or alteration of the platelet binding sites on the collagen molecule rather than to the reduced rate of polymerization. We chose to avoid this problem by modifying collagen to a state of accelerated, rather than retarded, polymerization. Monomeric collagen was reacted with 1-guanyl-3,5dimethylpyrazole nitrate to guanidinate the collagen lysine residues selectively. Guanidination was chosen because it leaves intact the arrangement of collagen polar groups shown to be important for the platelet: collagen interaction (4-6) and is unlikely to create new binding sites on the molecule. When monomeric collagen was guanidinated, the lag times in polymerization and platelet serotonin release were shortened proportionately. This observation, too, is consistent with the lag period in serotonin release by monomeric collagen being due in part to the time required for polymerization.

Hugues (24) has reported that glucosamine (final concentration $31 \mathrm{mM}$ ) strongly retards polymerization and mildly retards collagen-induced platelet aggregation. LeGrand, Caen, and Robert (25) reported that glucosamine inhibits platelet aggregation initiated by some of their soluble collagen preparations, but not by others. They attributed this difference to differences in the carbohydrate composition of their collagen samples. We found that when we used collagen demonstrated to be monomeric by electron microscopic examination, glucosamine retarded both polymerization and release. At the same concentration (17 mM), glucosamine had little or no effect on release produced by polymeric collagen or thrombin. Since we felt that the site of inhibition by glucosamine was not conclusively established by either of the previously mentioned groups of investigators, and since Jamieson, Urban, and Barber (7) and Katzman, Kang, and Beachy (8) have suggested that glucosamine inhibits collagen-induced platelet aggregation by blocking a membrane-bound platelet: collagen glucosyltransferase, we looked for a possible effect of glucosamine on the platelet. The data presented in this paper (Tables II and III and Fig. 6) show that glucosamine blocks only polymerization, not the subsequent interaction of the polymers with platelets or the response of the platelets to that interaction.

The exact mechanism by which glucosamine inhibits polymerization still remains to be established. However, since galactosamine was also an inhibitor, but glucose, galactose, and $N$-acetylglucosamine at the same concentration were not, we tentatively suggest that the inhibition is based on a nonspecific charge interaction with the collagen molecule that prevents the lateral association of monomers into polymers.

Finally, from the results of the experiments discussed above and from the observation that during the glucosamine-extended lag period in polymerization there is no release of serotonin (Fig. 5), we conclude that collagen monomers cannot effectively interact with platelets. Still to be demonstrated is whether platelets will adhere to monomers even though they are not stimulated by them. Similarly, the minimum degree of quaternary structure required for an effective platelet: collagen interaction remains to be established. From our data it appears that even small polymers are more effective than monomers, since preincubation of monomeric collagen for times at which polymerization was barely detectable (Fig. 1A) was sufficient to shorten the lag time markedly in serotonin release (Fig. 1B).

Recently two other groups of investigators have arrived at conclusions similar to those presented here $(29,30)$. Both groups used platelet aggregation rather than the release reaction as an index of the platelet: collagen interaction. There are some slight discrepancies between their results and ours. For example, Jaffe and Deykin (29) found the lag time for platelet aggregation to be independent of monomer concentration. Superficially, this observation would seem to be in contradiction to the established kinetics of polymerization (31). Polymers form faster in more concentrated solutions. Our data show that the rate of serotonin release is, as predicted, dependent on collagen concentration. Jaffe and Deykin's observation may have resulted from synergy of released ADP with the small amounts of collagen they used in their assays.

In apparent contradiction to the conclusions discussed in this paper, Kang and his co-workers $(8,11)$ have reported that at high concentrations $(1 \mathrm{mg} / \mathrm{ml})$ there is platelet-aggregating activity associated with collagen $\alpha 1-\mathrm{CB} 5 \mathrm{CNBr}$ peptide and $\alpha 1$ chains. At the temperature 
used in their assay $\left(37^{\circ} \mathrm{C}\right)$, neither of these pieces of the collagen molecule should possess native tertiary or quaternary structure. Of all of the species tested, only the peptides from chick skin had aggregating activity. Our comments regarding the role of quaternary structure may, therefore, not apply to chick skin collagen at high concentration. Our own unpublished data show that $\alpha 1$ chains $(2 \mathrm{mg} / \mathrm{ml})$ derived from bovine AS skin collagen do not cause serotonin release or form polymers.

Finally, the conclusions presented in this paper have relevance to other investigations of the platelet: collagen interaction. There has been much speculation that platelets interact with the collagen carbohydrate groups via a membrane-bound platelet: collagen glucosyltransferase $(7-11,32,33)$. The studies published to date contain notable contradictions. Some of these may be due to a failure to take into account the state of the quaternary structure of the collagen used to initiate aggregation. For example, Chesney, Harper, and Colman (10) reported that collagen on which the galactose residues had been oxidized by treatment with galactose oxidase no longer initiated platelet aggregation. This observation is in accord with the glucosyltransferase theory. But Muggli and Baumgartner (30) have recently shown that galactose oxidase-treated collagen polymerizes far more slowly than untreated collagen. Once it has polymerized, the oxidized collagen produces normal platelet aggregation. Similarly, we found that collagen freed of carbohydrate by reaction with periodate no longer causes serotonin release or polymerizes (unpublished data).

\section{ACKNOWLEDGMENTS}

Our thanks to Mr. Smith McKnight and Mr. Steven Wolinsky for their valuable assistance, and to Dr. John Harris for his advice during the preparation of this manuscript.

This work was supported by grants from the U. S. Public Health Service (HD-00669, AM-01825, and GM-00035).

\section{REFERENCES}

1. Zucker, M. B., and J. Borelli. 1962. Platelet clumping produced by connective tissue suspensions and by collagen. Proc. Soc. Exp. Biol. Med. 109: 779-787.

2. Holmson, H., H. J. Day, and H. Stormorken. 1969. The blood platelet release reaction. Scand. J. Haematol. Suppl. 8: 1-26.

3. Mustard, J. F., and M. A. Packham. 1970. Factors influencing platelet function: adhesion, release and aggregation. Pharmacol. Rev. 22: 97-187.

4. Wilner, G. D., H. L. Nossel, and E. C. LeRoy. 1968. Aggregation of platelets by collagen. J. Clin. Invest. 47: 2616-2621.

5. Nossel, H. L., G. D. Wilner, and E. C. LeRoy. 1969. Importance of polar groups for initiating blood coagulation and aggregating platelets. Nature (Lond.). 221 : 75-76.

6. Wilner, G. D., H. L. Nossel, and T. L. Procupez. 1971. Aggregation of platelets by collagen: polar active sites of insoluble collagen. Am. J. Physiol. 220: 1074 1079.

7. Jamieson, G. A., C. L. Urban, and A. J. Barber. 1971. Enzymatic basis for platelet: collagen adhesion as the primary step in haemostasis. Nat. New Biol. 234: 5-7.

8. Katzman, R. L., A. H. Kang, and E. H. Beachey. 1973. Collagen-induced platelet aggregation: involvement of an active glycopeptide fragment. Science (Wash. D. C.). $181: 670-671$.

9. Puett, D., B. K. Wasserman, J. D. Ford, and L. W. Cunningham. 1973. Collagen-mediated platelet aggregation. Effects of collagen modification involving the protein and carbohydrate moieties. J. Clin. Invest. 52: 2495-2506.

10. Chesney, E. McI., E. Harper, and R. Colman. 1972. Critical role of the carbohydrate side chains of collagen in platelet aggregation. J. Clin. Invest. 51: 2693-2701.

11. Kang, A. H., E. H. Beachey, and R. L. Katzman. 1974. Interaction of an active glycopeptide from chick skin collagen ( $\alpha$ 1-CB5) with human platelets. J. Biol. Chem. 249: 1054-1059.

12. Hodge, A. J., and F. O. Schmitt. 1960. The charge profile of the tropocollagen macromolecule and the packing arrangement in native-type collagen fibrils. Proc. Natl. Acad. Sci. U. S. A. 46: 186-197.

13. Packham, M. A., M. A. Guccione, P. L. Chang, and J. F. Mustard. 1973. Platelet aggregation and release: effects of low concentrations of thrombin or collagen. Am. J. Physiol. 225:38-47.

14. Holmsen, H. A., A.-C. Østvold, and H. J. Day. 1973. Behavior of endogenous and newly absorbed serotonin in the platelet release reaction. Biochem. Pharmacol. 22: 2599-2608.

15. Ardlie, N. G., D. W. Perry, M. A. Packham, and J. F. Mustard. 1971. Influence of apyrase on stability of suspensions of washed rabbit platelets. Proc. Soc. Exp. Biol. Med. 136: 1021-23.

16. Mustard, J. F., D. W. Perry, N. G. Ardlie, and M. A Packham. 1972. Preparation of suspensions of washed platelets from humans. Br. J. Haematol. 22: 193-204.

17. Gross, J., J. H. Highberger, and F. O. Schmitt. 1954 Collagen structure considered as states of aggregation of a kinetic unit. The tropocollagen particle. Proc. Natl. Acad. Sci. U. S. A. 40: 679-688.

18. Bensusan, H. B., V. R. Mumaw, and A. W. Scanu. 1962. Fiber formation from solutions of collagen. IV. On the role of the basic amino acid residues. Biochemistry. 1 : 215-223.

19. Wood, G. C., and M. K. Keech. 1960. The formation of fibrils from collagen solutions. I: The effect of experimental conditions. Biochem. J. 75: 588-598.

20. Wolfe, S. M., and N. R. Shulman. 1970. Inhibition of platelet energy production and release reaction by $\mathrm{PGE}_{1}$, theophylline and cAMP. Biochem. Biophys. Res. Commun. 41: 128-134.

21. Massini, P., and E. F. Luscher. 1971. The induction of the release reaction in human blood platelets by close cell contact. Thromb. Diath. Haemorrh. 25: 13-20.

22. Mills, D. C. B., I. A. Robbs, and G. C. K. Roberts. 1968. The release of nucleotides, 5-hydroxytryptamine and enzymes from human blood platelets during aggregation. J. Physiol. (Lond.). 195: 715-729.

23. Zamenhoff, S. 1957. Preparation and assay of deoxyribonucleic acid from animal tissue. Methods Enzymol. 3: 696-704.

24. Hugues, J. 1968. Some remarks concerning platelet 
aggregation induced by collagen. Exp. Biol. Med. 3: 145-154.

25. LeGrand, Y., J. P. Caen, and L. Robert. 1968. Effect of glucosamine on the platelet-collagen reaction. Proc. Soc. Exp. Biol. Med. 127: 941-943.

26. Caen, J. P., Y. LeGrand, and Y. Sultan. 1970. Plateletcollagen interactions. Thromb. Diath. Haemorrh. Suppl. 40: 181-197.

27. Jalenska, M. M., Z. Wegrzynowicz, A. M. Dancewicz, and M. Kopeć. 1973. Thromb. Res. 2: 41-54.

28. Simons, E. R., E. Harper, C. M. Chesney, E. Samberg, and R. W. Colman. 1973. Collage conformation, fibril formation, and platelet aggregation. Proceedings of the American Society of Hematology. 16th Annual Meeting, Chicago, Ill. 1-4 December 1973. Abstr. 250. 120.

29. Jaffe, R., and D. Deykin. 1974. Evidence for a struc- tural requirement for the aggregation of platelets by collagen. J. Clin. Invest. 53: 875-883.

30. Muggli, R., and H. R. Baumgartner. 1973. Collagen induced platelet aggregation: requirement for tropocollagen multimers. Throm. Res. 3: 715-728.

31. Wood, G. C. 1960. The formation of fibrils from collagen solution. II. A mechanism of collagen-fibril formation. Biochem. J. 75 : 598-605.

32. Bosman, H. B. 1971. Platelet adhesiveness and aggregation: the collagen: glycosyl, polypeptide: $N$-acetylgalactosaminyl and glycoprotein: galactosyl transferase of human platelets. Biochem. Biophys. Res. Commun. 43: 1118-1124.

33. Barber, A. J., and G. A. Jamieson. 1971. Characterization of membrane-bound collagen galactosyltransferase of human blood platelets. Biochim. Biophys. Acta. 252: 546-552. 